\title{
ANALISIS STOK KARBON PADA SEDIMEN MANGROVE DI DESA BATURAPA KECAMATAN LOLAK KABUPATEN BOLAANG MONGONDOW
}

\author{
(CARBON STOCK ANALYSIS OF MANGROVE SEDIMENT IN BATURAPA VILLAGE, \\ LOLAK DISTRICT, BOLAANG MONGONDOW REGENCY)
}

\section{Andreas Marbun ${ }^{1 \star}$, Antonius P Rumengan1, Joshian N.W. Schaduw', Carolus P. Paruntu $^{1}$, Ping Astony Angmalisang ${ }^{1}$, Victoria E.N. Manoppo ${ }^{2}$}

1. Program Studi IImu Kelautan, FPIK Unsrat Manado.

2. Program Studi Agrobisnis Perikananm FPIK Unsrat Manado

*e-mail : marbunandreas10@gmail.com

\section{ABSTRACT}

Global warming is one of the issues in the world today, it can be seen by the occurrence of high earth temperatures which are directly related to greenhouse gases. Mangrove forests are reported to be able to mitigate global warming because of their ability to store carbon in biomass and sediment well. A study was conducted to determine soil sediment density, percentage of organic carbon, carbon density and estimation of carbon deposits in mangrove ecosystem sediments in Baturapa Village, Lolak District, Bolaang Mongondow Regency. Mangrove sediment sampling was carried out using Purpose Sampling techniques and the data obtained were analyzed using the Loss on Ignition method. The results showed the average value of soil density of all stations is $0.39 \mathrm{~g} / \mathrm{cm} 3 \pm 0.04$. The average value of organic carbon percentage at all stations is $10.57 \mathrm{C} \% \pm 4.87$. The average total carbon content at all stations is $398.82 \mathrm{MgC}$ ha- $1 \pm 14.40$. Mangrove forests are able to accommodate large amounts of carbon in both biomass and sediment.

Keywords : Carbon Stock Analysis, Mangrove Sediment, Purpose Sampling, LOI (Loss On Ignition), Baturapa Village, Bolaang Mongondow Regency.

Pemanasan global adalah salah satu isu di dunia saat ini, bisa dilihat dengan adanya peristiwa tingginya suhu bumi yang terkait langsung dengan gas-gas rumah kaca. Hutan mangrove dilaporkan mampu memitigasi pemanasan global karena kemampuannya menyimpan karbon di biomassa dan sedimen dengan baik. Telah dilakukan penelitian untuk mengetahui densitas sedimen tanah, presentase karbon organik, densitas karbon dan estimasi simpanan karbon pada sedimen ekosistem mangrove di Desa Baturapa Kecamatan Lolak Kabupaten Bolaang Mongondow. Pengambilan sampel sedimen mangrove dilakukan dengan teknik Purpose Sampling dan data yang diperoleh dianalisis dengan metode Loss on Ignition. Hasil penelitian menunjukan nilai rata-rata densitas tanah seluruh stasiun yaitu sebesar $0,39 \mathrm{~g} / \mathrm{cm}^{3} \pm 0,04$. Nilai rata-rata presentase karbon organik pada seluruh stasiun yaitu sebesar $10,57 \mathrm{C} \% \pm 4,87$. Nilai rata-rata kandungan karbon total pada seluruh stasiun yaitu sebesar $398,82 \mathrm{MgC}^{-1} \pm 14,40$. Hutan mangrove mampu menampung kandungan karbon dengan jumlah besar baik di biomassa dan sedimen.

Kata Kunci : Analisis Stok Karbon, Sedimen Mangrove, Purpose Sampling, LOI (Loss On Ignition), Desa Baturapa, Kabupaten Bolaang Mongondow. 


\section{PENDAHULUAN}

Pemanasan global adalah salah satu isu di dunia saat ini, bisa dilihat dengan adanya peristiwa tingginya suhu bumi yang terkait langsung dengan gas-gas rumah kaca. (Dharmawan dan Siregar, 2008; Verisandria, dkk., 2018; Zulkarnain, dkk., 2016).

Menurut Rumengan, dkk, (2018) Ekosistem mangrove adalah salah satu ekosistem wilayah pesisir yang sangat potensial sebagai penyedia unsur hara bagi yaitu sebagai penyedia nutrien bagi biota perairan, tempat pemijahan dan asuhan bagi berbagai macam biota, penahan abrasi, amukan angin, taufan dan tsunami, penyerap limbah, dan penyimpanan karbon (Ontorael dkk., 2012; Rangan, 2010).

Salah satu penyebab tingginya kandungan $\mathrm{CO}_{2}$ di bumi adalah mode transportasi yang meningkat dan industry. Hal ini dibarengi dengen semaking meningkatnya populasi manusia di bumi. Aktivitas antropogenik diketahui dapat meningkatkan tingginya kandungan $\mathrm{CO}_{2}$ (Gypens et al., 2009 dalam Restu et al., 2013).

Mangrove memanfaatkan karbon untuk proses fotosintesis dan menyimpannya dalam betuk biomassa, baik pada bagian atas dan bagian bawah (Donato, $d k k$,.2012). Ekosistem mangrove adalah hutan yang paling dominan penyimpan karbon dari hutan lainnya, dengan sebagian besar dialokasikan secara proporsional lebih banyak karbon di bawah tanah (Alongi, 2012). Menurut Murray, dkk., (2011) sedimen mangrove mempunyai Selanjutnya analisis sampel dilaksanakan di Laboratorium Analisis
Ekosistem mangrove sangat penting dalam upaya mitigasi pemanasan global, yakni sebagai penyimpan karbon terbaik disbanding semua tipe hutan lainnya di bumi

ekosistem lainnya dan perairan pesisir sekitarnya. Mangrove merupakan ekosistem peralihan antara daratan dan lautan, juga mempunyai manfaatnyata bagi kehidupan, baik manfaat ekologi

kemampuan untuk menyimpan karbon lebih tinggi dari pada pohon mangrove itu sendiri.

Menurut, Verisandria, dkk., (2018), dari hasil penelitiannya untuk simpanan karbon di Kelurahan Meras pada Kawasan Taman Nasional Bunaken yaitu sebesar 157,01 Mg ha1. Kemudian pada penelitian simpanan karbon yang dilakukan Rumengan, $d k k$, 2018, di Teluk Totok, Minahasa Tenggara sebesar $286.18 \mathrm{Mg}$ ha-1.

Teluk Labuan Uki memiliki wilayah konservasi ekosistem mangrove yang berada di Desa Baturapa Kecamatan Lolak Kabupaten Bolaang Mongondow yang belum diteliti berapa kandungan karbon yang tersimpan sehingga itu yang menjadi tujuan penelitian ini.

\section{METODE PENELITIAN}

\section{Tepat dan Waktu Penelitian}

Penelitian dilaksanakan selama 4 bulan (April-Agustus 2019). Sampel sedimen didapat dari Desa Baturapa Kecamatan Lolak Kabupaten Bolaang Mongondow. Lokasi pengambilan sampel dapat di lihat pada gambar 1.

Kesehatan, Politeknik Kesehatan Manado, Sulawesi Utara. 


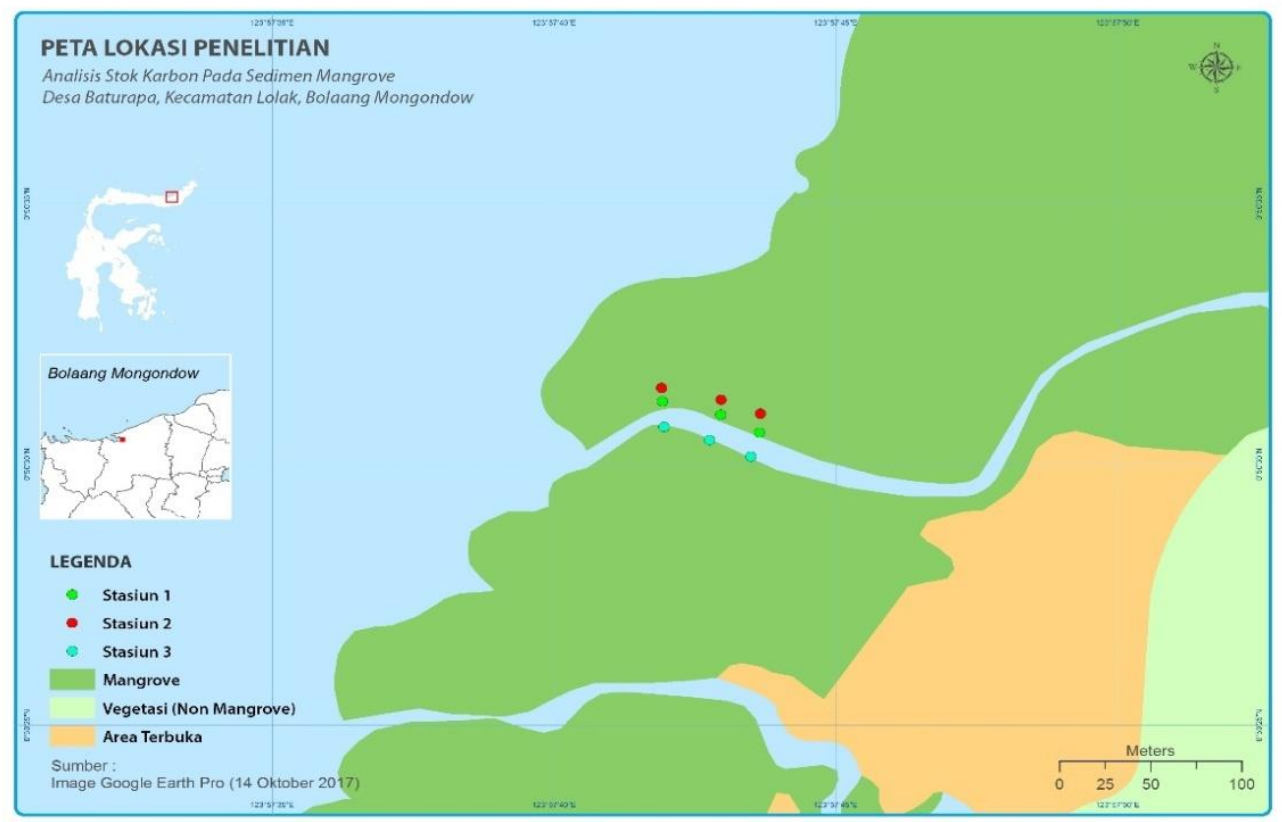

Gambar 1. Lokasi Pengambilan Sampel

Alat dan Bahan

Kegiatan penelitian ini dikerjakan baik

di

apangan maupun di ruang kerja
Laboratorium dengan menggunakan sejumlah peralatan dan bahan seperti dicantumkan dalam Tabel 1.

Tabel 1. Alat dan Bahan untuk pengambilan Sampel sedimen di lokasi

\begin{tabular}{l|l}
\hline \multicolumn{1}{c}{ Alat } & \multicolumn{1}{c}{ Kegunaan } \\
\hline Sedimen corer & $\begin{array}{l}\text { Alat untuk mengambil sampel tanah yang berbentuk seperti tabung panjang } \\
\text { untuk mendapatkan sampel sedimen pada kedalaman tertentu. }\end{array}$ \\
\hline Perahu & Untuk memudahkan transportasi ke lokasi pengambilan sampel. \\
\hline Kantong sampel & Untuk menyimpan sampel sebelum di analisi di laboratorium. \\
\hline $\begin{array}{l}\text { GPS (Aplikasi Peta } \\
\text { Koordinat) }\end{array}$ & Untuk menentukan titik lokasi pengambilan data. \\
\hline Meteran & $\begin{array}{l}\text { Untukmengukur kedalaman sampel sedimen dan memudahkan dalam } \\
\text { menentukan sampel yang akan diambil }\end{array}$ \\
\hline Kamera handphone & Untuk dokumentasi kegiatan selama di lokasi. \\
\hline Kertas label & Untuk memberikan tanda keterangan sampel yang diambil. \\
\hline Alat tulis & $\begin{array}{l}\text { Untuk mencatat hal-hal penting terkait dengan pengambilan sampel di } \\
\text { lokasi. }\end{array}$ \\
\hline
\end{tabular}

Tabel 2. Alat yang digunakan di laboratorium

Alat

Oven

Timbangan Analitik

Timbangan digital

\section{Kegunaan}

Untuk mengeringkan sampel sedimen, sebelum dibakar dalam muffle furnace

Untuk menimbang sampel sedimen dengan ketelitian tinggi (4 angka dibelakang koma)

Untuk menimbang sampel sedimen dengan ketelitian sedang (2 - 3 angka dibelakang koma) 


\begin{tabular}{cl}
\hline $\begin{array}{c}\text { Cawan Sampel (Crucible } \\
\text { porcelain) }\end{array}$ & $\begin{array}{l}\text { Sebagai wadah untuk menempatkan sampel selama pengeringan di } \\
\text { dalam oven }\end{array}$ \\
\hline Mortar & Untuk menghaluskan sampel \\
\hline Crucible porcelain & $\begin{array}{l}\text { Untuk menempatkan sampel (setelah ditimbang } 3 \mathrm{gram} \text { ) selama } \\
\text { pembakaran sampel dalam muffle furnace }\end{array}$ \\
\hline Muffle Furnace & Untuk membakar sampel (pengabuan) \\
\hline
\end{tabular}

\section{Pengambian dan Penanganan Sampel di Lokasi}

\section{Pengambilan Sampel}

Sampel sedimen diperoleh dari 3 stasiun di Desa Baturapa Kecamatan Lalok Kabupaten Bolaang Mongondow. Prosedur yang digunakan dalam pengambilan sampel adalah metode survei seperti yang dilakukan oleh Mahasani, dkk., (2015), yaitu pengamatan dan pengambilan sampel langsung di lapangan. Pengambilan sampel untuk mengetahui stok karbon pada ekosistem mangrove difokuskan pada bahan organik tanah atau sedimen pada ekosistem mangrove yang dilakukan dengan metode purpose Sampling atau menentukan langsung titik lokasi pengambilan sampel.

Pada masing-masing lokasi pengambilan sampel ditentukan 3 (tiga) titik pada ekosistem mangrove yang mewakili bagian depan yaitu lebih dekat ke arah laut (titik pertama), bagian tengah (titik kedua), dan bagian belakang (titik ketiga) bagian yang lebih dekat ke pemukiman untuk mewakili pengambilan sampel pada lokasi. Kemudian pada masing-masing titik diambil 3 sampel berdasarkan kedalaman. Sehingga jumlah sampel yang diperoleh disetiap lokasi sebanyak 9 (sembilan) sampel. Total sampel keseluruhan yang dianalisis adalah 27 sampel.

\section{Penanganan Sampel}

Data yang diperlukan untuk menganalisis dan mendapatkan presentase stok karbon organik dalam tanah adalah kedalaman sampel tanah, interval sampel yang diambil dan densitas tanah (kerapatan massa jenis). Untuk mengetahui hal tersebut, tahapan kerja yang perlu dilakukan adalah sebagai berikut:

a) Sebelum melakukan pengambilan sampel, sampah organik dan daun hidup (jika ada) dibersihkan dari permukaan tanah;

b) Kemudian melakukan coring dengan memasukkan corer ke dalam tanah secara vertikal di titik yang telah ditentukan sampai kedalaman mencapai pangkal corer. Corer diputar untuk memotong akar halus yang terdapat dalam tanah. Lalu corer ditarik perlahan dari dalam tanah sambil terus diputar untuk mempertahankan agar sampel sedimen yang diambil tetap penuh dan lengkap;

c) Sampel yang telah diperoleh dibelah secara horizontal, dan dibagi berdasarkan 3 kedalaman (3 sampel), yaitu $0-30 \mathrm{~cm}$, 30-60 cm dan 60-100 cm. Tidak seluruhnya sampel sedimen diambil, tetapidengan cara menentukan interval dari kedalaman masing-masing sampel 
tersebut dan sisanya dibuang. Sampel pada kedalaman 0-30 $\mathrm{cm}$ hanya diambil pada kedalaman $10-20 \mathrm{~cm}$, sampel pada kedalaman $30-60 \mathrm{~cm}$ hanya diambil pada kedalaman $40-50 \mathrm{~cm}$ dan kedalaman 60 $100 \mathrm{~cm}$ hanya diambil pada kedalaman $75-85 \mathrm{~cm}$;.

d) Sampel yang diperoleh kemudian dimasukkan ke dalam kantong plastik sampel dan diberi label pada setiap kantong untuk memudahkan identifikasi dan analisis di laboratorium;

e) Sampel tersebut disimpan didalam kulkas agar dapat bertahan sampai pada saatnya dianalisis di laboratorium.

\section{Analisis Sampel dan Pengolahan Data}

\section{Analisis Sampel di Laboratorium}

Setelah pengambilan sampel di lokasi selesai, kemudian sampel yang diperoleh dianalisis di laboratorium dengan metode loss on ignition (LOI) (Howard dkk., 2014). Tahapan analisis tersebut adalah :

a) Sampel sedimen yang diperoleh ditempatkan dalam wadah yang sudah disiapkan. Kemudian dikeringkan di dalam oven dengan suhu $60^{\circ} \mathrm{C}$ selama 48 jam.

b) Setelah sampel kering kemudian digerus atau dihaluskan dengan menggunakan mortar agar kondisi setiap sampel menjadi homogen. Kemudian setiap sampel yang sudah dihaluskan tersebut ditempatkan kembali kedalam kantong plastik sampel;

c) Sampel tersebut kemudian diambil dengan sendok kecil dan ditimbang sebanyak 3 gram dan ditempatkan pada wadah yang sudah disiapkan. Kemudian dibakar dengan suhu $450^{\circ} \mathrm{C}$ selama 4 jam. Setelah itu sampel tersebut ditimbang kembali dan hasilnya dicatat.

\section{Pengolahan Data}

Data yang dihitung adalah kedalaman sampel sedimen, densitas tanah, densitas karbon, estimasi karbon dan persentase karbon organik pada sedimen. Adapun perhitungan yang digunakan dalam menganalisis data sebagai berikut (Howard dkk., 2014) :

1. Densitas tanah merupakan berat partikel per satuan volume tanah beserta porinya. Rumus yang digunakan untuk menghitung densitas tanah (BD) disajikan pada persamaan 1:

Densitas tanah $\left(\mathrm{g} / \mathrm{cm}^{3}\right) \quad=$

$\frac{\text { oven-dry mass }(\mathrm{g})}{\text { sample volume }\left(\mathrm{cm}^{3}\right)}$

Keterangan :

Densitas tanah $=$ Kadar isi substrat lumpur $\left(\mathrm{gram} / \mathrm{cm}^{3}\right)$

oven-dry mass=Massa sampel yang dikeringkan (gram)

sample volume $\left(\mathrm{cm}^{3}\right) \quad=$ Volume sampel $\left(\mathrm{cm}^{3}\right)$

2. Pengabuan Kering (loss on ignition) dihitung menggunakan persamaan 2:

$\% \mathrm{BO}=((\mathrm{Wo}-\mathrm{Wt}) / \mathrm{Wo} \times 100)$.

Keterangan :

$\% \mathrm{BO}=$ Persentase bahan organik sedimen yang hilang pada proses pembakaran.

Wo $=$ Berat keringsebelum pembakaran (gram)

$\mathrm{Wt}=$ Berat akhir setelah pembakaran (gram)

3. Konversi persentase bahan organik menjadi persentase karbon dihitung menggunakan persamaan 3 :

$\% \mathrm{C}=(0,580) \mathrm{X} \% \mathrm{BO}$

Keterangan :

$\% \mathrm{C}=$ Kandungan Karbon bahan sedimen organik 
$\% \mathrm{BO}=$ Persentase bahan organik sedimen (pengabuan)

$0,580=$ Konstanta untuk mengkonversi \% bahan organik menjadi \%C organik.

4. Kandungan densitas karbon pada tanah diestimasi dengan persamaan 5:

Soil $C$ density $\left(\mathrm{g} \mathrm{C} \mathrm{cm}^{-3}\right)=\% \mathrm{C} \times \mathrm{BD}$ (densitas tanah)

Keterangan :

Soil $C$ density $\left(\mathrm{g} \mathrm{C} \mathrm{cm}^{-3}\right)=$ Densitas Karbon

\section{HASIL DAN PEMBAHASAN}

\section{Densitas Tanah}

Densitas tanah merupakan bobot massa tanah pada kondisi yang telah dikering/ovenkan per satuan volum. Dari hasil analisis, diketahui bahwa tanah pada masing-
$\% \mathrm{C}=$ Kandungan karbon bahan sedimen organik

$B D=$ Densitas tanah $\left(\mathrm{g} / \mathrm{cm}^{3}\right)$

5. Kandungan karbon total:

Soil $C\left(\mathrm{MgC} \mathrm{ha}^{-1}\right)=\mathrm{BD} \times \mathrm{SDI}($ Soil Depth Interval) $\mathrm{x} \% \mathrm{C}$

Keterangan :

Soil $C\left(\mathrm{MgC} \mathrm{ha}^{-1}\right)=$ Estimasi Simpanan Karbon

$\mathrm{BD}=$ Densitas tanah $\left(\mathrm{g} / \mathrm{cm}^{3}\right)$

SDI = Interval Kedalaman Sampel $(\mathrm{cm})$

masing kedalaman memiliki nilai densitas tanah yang berbeda. Volume sampel diperoleh dari hasil pengukuran tinggi interval sampel dan diameter corer.

Nilai rata-rata densitas tanah disetiap stasiun di lokasi dapat dilihat pada gambar 2:

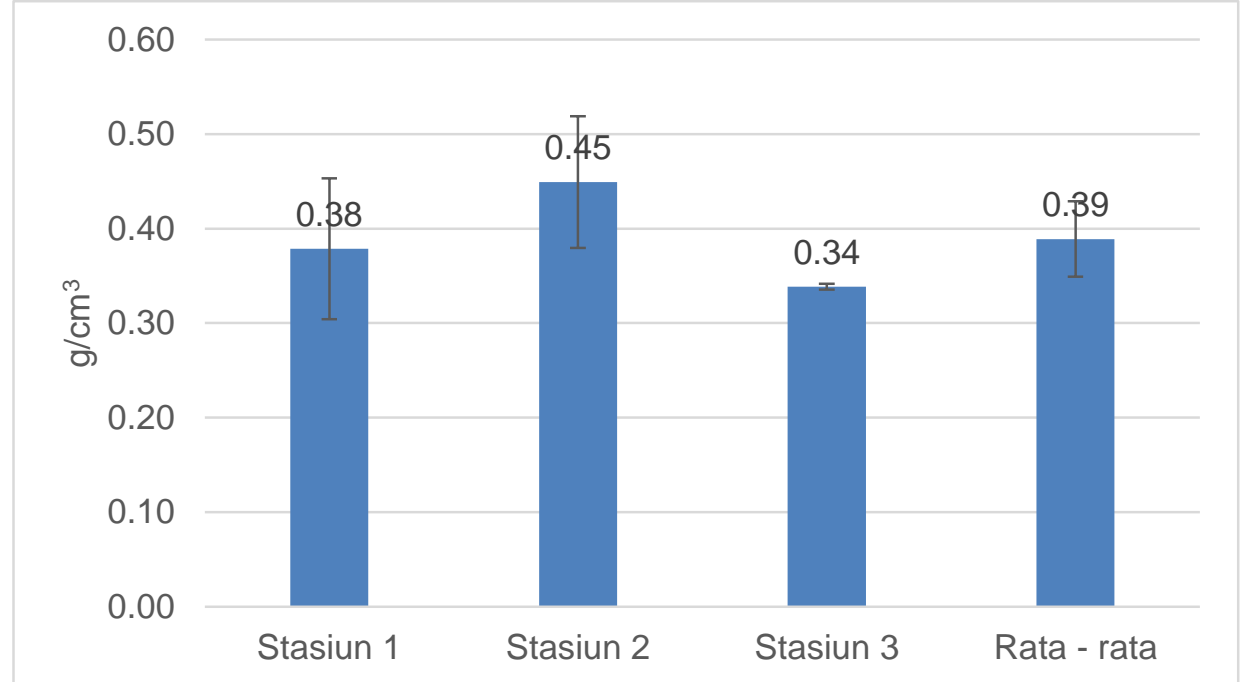

Gambar 2. Grafik nilai rata-rata densitas tanah.

Pada gambar 2, dapat dilihat nilai ratarata densitas tanah pada keseluruhan stasiun yaitu sebesar $0,39 \mathrm{~g} / \mathrm{cm}^{3} \pm 0,04$. Nilai densitas tanah yang diperoleh dari penelitian ini lebih besar dibandingkan dengan nilai densitas tanah yang diperoleh dari hasil penelitian stok karbon tanah yang dilakukan oleh (Marchio, $d k k, .2016$ ) yaitu sebesar $0,25 \mathrm{~g} / \mathrm{cm}^{3} \pm 0,02$ dan nilai densitas tanah yang diperoleh dari penelitian ini lebih kecil dibandingkan dengan nilai densitas tanah yang diperoleh dari hasil penelitian yang dilakukan di hutan mangrove bekas tambak di Bali oleh (Mahasani dkk., 2015), yaitu sebesar $0,139 \mathrm{~g} / \mathrm{cm}^{3}$. Hal ini dikarenakan adanya perbedaan interval yang digunakan dalam pengambilan sampel sedimen. Interval yang digunakan pada penelitian di hutan mangrove bekas tambak di Bali, yaitu $5 \mathrm{~cm}$. 


\section{Karbon Organik Sedimen Mangrove}

Karbon organik pada sedimen merupakan salah satu penyusun senyawa organik diperairan. Menurut (Supriyadi, 2008), karbon organik merupakan prioritas untuk peningkatan kualitas tanah dan untuk penyimpanan karbon.

Nilai persentase karbon organik pada sedimen untuk penelitian ini didapat dari pengolaan data, berbeda disetiap masingmasing stasiun. Perolehan nilai persentase karbon organik didapatkan dari hasil metode pengabuan LOI (Loss on Ignationl) untuk mengetahui bahan organik dan dikonversi menjadi karbon organik. Nilai rata-rata persentase karbon organik seluruh stasiun dapat dilihat pada gambar 3 .

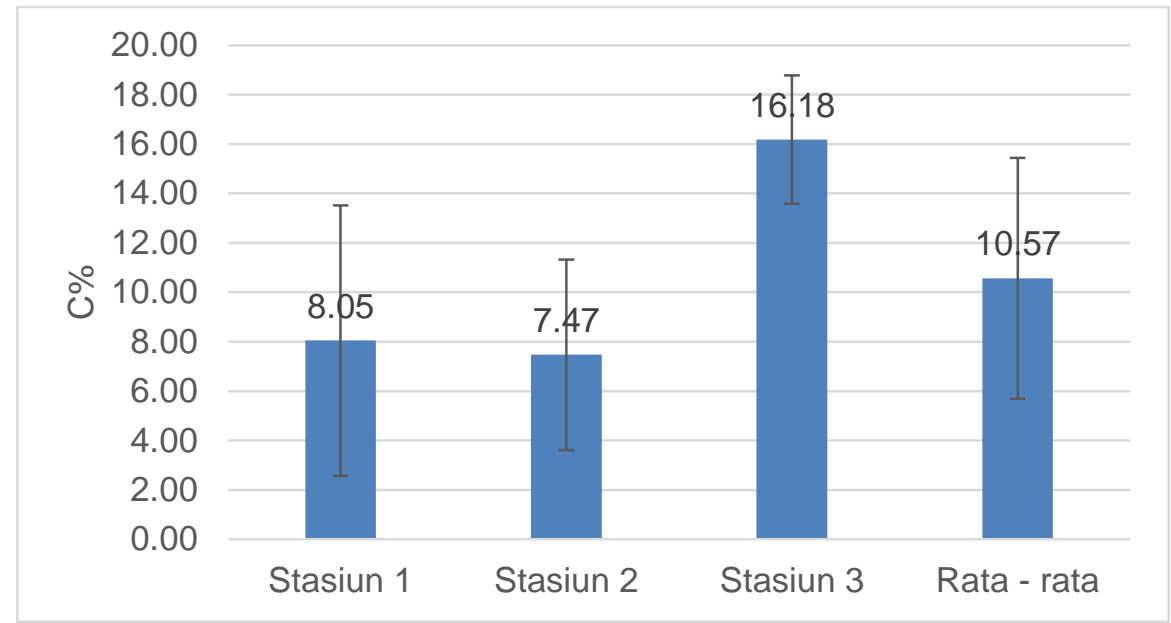

Gambar 3. Grafik nilai rata-rata presentasi karbon organik

Dari gambar 3, dapat dilihat bahwa nilai rata-rata persentase karbon organik sedimen pada keseluruhan stasiun yaitu sebesar 10,57 $\mathrm{C} \% \pm 4,87$.Nilai persentase karbon organik pada penelitian ini lebih kecil dibandingkan dengan persentase karbon organik pada penelitian yang dilakukan oleh (Indraiswari dkk., 2018) di hutan mangrove alami Perancak, Jembrana,Bali yaitu $50,23 \mathrm{C} \%$ dan terletak pada bagian dalam tanah.

Perbandingan dengan penelitian lainnya mengenai nilai persentase karbon organik sedimen yaitu pada penelitian yang dilakukan

\section{Rata-rata Karbon Total Seluruh Stasiun}

Sebaran nilai rata-rata kandungan karbon pada keseluruhan stasiun. Hal ini oleh (Verisandria dkk., 2018) di Taman Nasional Bunaken Bagian Utara lebih besar dengan nilai persentase karbon organik yang diperoleh yaitu $22,01 \mathrm{C} \%$.

Menurut Madjid (2007) dalam Dewanti $d k k$.(2016), sumber primer bahan organik tanah berasal dari jaringan organik tanaman yang dapat berupa daun, ranting dan cabang, batang, buah dan akar. Hasil pelapukan dari daun-daun yang berjatuhan dari tumbuhan serta organisme yang berasosiasi dengan tumbuhan yang kemudian mati dan terdegradasi dalam endapan sedimen. dipengaruhi oleh kondisi densitas tanah yang telah dianalisis pada masing-masing stasiun dapat dilihat pada gambar 4 . 


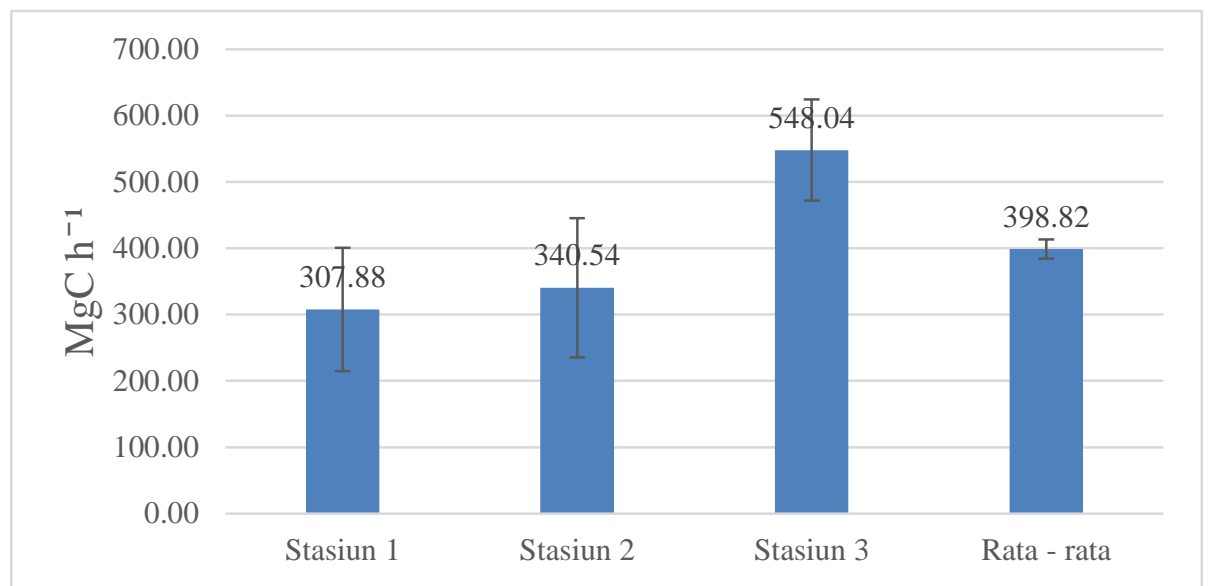

Gambar 4. Grafik rata-rata Kandungan karbon total setiap stasiun.

Nilai rata-rata kandungan karbon total pada keseluruhan stasiun yaitu sebesar 398,82 $\mathrm{MgC}$ ha $^{-1} \pm 14,40$. Hasil yang diperoleh lebih kecil dibandingkan dengan hasil penelitian dari (Donato dkk., 2012) yaitu sebesar 1218 Mg ha1. Tapi hasil penelitian ini lebih besar dari hasil penelitian yang dilakukan oleh (Suryono $d k k, .2018)$ di Hutan Mangrove Perancak
Jembrana, Bali memperoleh nilai kandungan karbon sebesar 57,69 MgC ha-1 dan (Syukri, 2017) yaitu 196,39 MgC ha-1. Menurut, (Mahasani $d k k ., 2016$ ) terdapat berbagai faktor yang mempengaruhi simpanan karbon dalam tanah, diantaranya faktor lingkungan seperti pemanfaatan lahan dan faktor fisika-kimia tanah seperti suhu, $\mathrm{pH}$, pori-pori, tekstur, bulk density, dll. 
Tabel 3. Hasil Analisis Sampel Seluruh Stasiun.

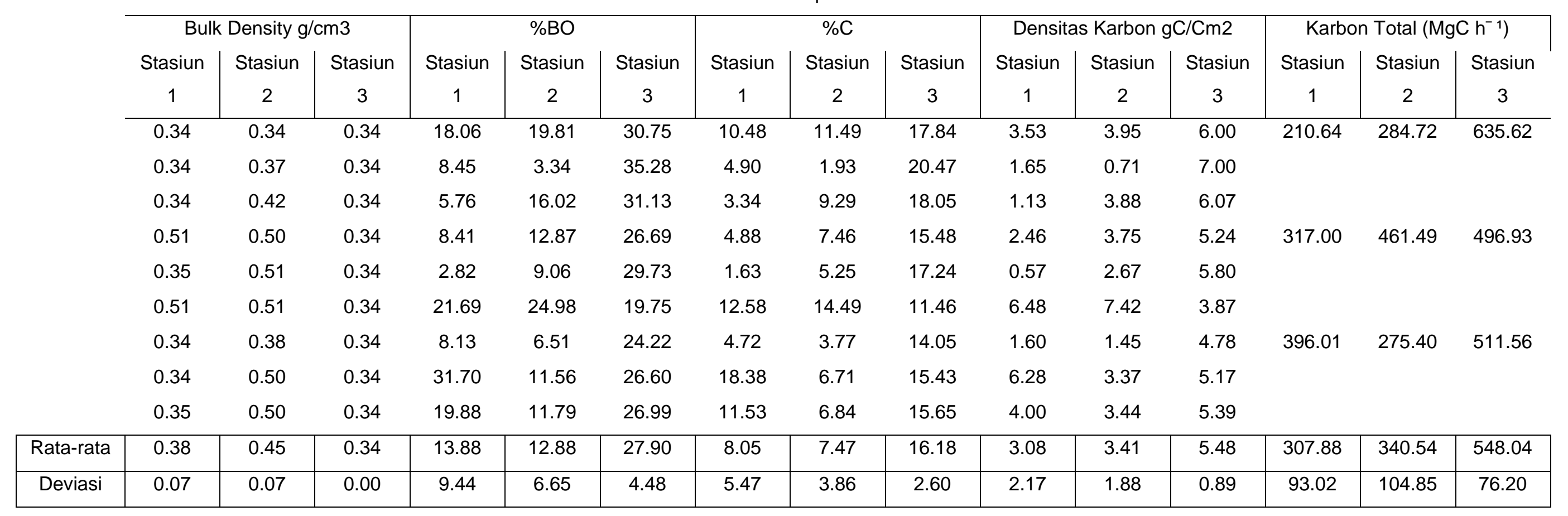




\section{KESIMPULAN DAN SARAN}

Kesimpulan

Dari pembahasan dapat ditarik kesimpulan, nilai rata - rata densitas tanah pada keseluruhan stasiun yaitu sebesar 0,39 $\mathrm{g} / \mathrm{cm}^{3} \pm 0,04$ kemudian besaran nilai rata - rata presentase karbon organik sedimen mangrove pada seluruh stasiun yaitu sebesar $10,57 \mathrm{C} \% \pm$ 4,87 dan rata - rata kandungan karbon total pada seluruh stasiun di Desa Baturapa Kecamatan Lolak Kabupaten Bolaang Mongondow adalah sebesar 398,82 $\mathrm{MgC} \mathrm{ha}^{-1} \pm$ 14,40 .

\section{Saran}

Berdasarkan hasil yang diperoleh selama penelitian, saran yang dapat diajukan yaitu sebaiknya pengukuran estimasi stok karbon pada sedimen ekosistem mangrove dilakukan secara berkelanjutan untuk mengetahui bagaimana perubahan kandungan karbon secara temporal.

\section{DAFTAR PUSTAKA}

Alongi, D. M. (2012). Carbon Sequestration In Mangrove Forests. Carbon Management, 3(3), 313-322. Https://Doi.Org/10.4155/Cmt.12.20

Dharmawan, I. W. S., \& Siregar, C. A. (2008). Karbon Tanah Dan Pendugaan Karbon Tegakan Avicennia Marina(Forsk.) Vierh. Di Ciasem, Purwakarta. Jurnal Penelitian Hutan Dan Konservasi Alam, 5(4), 317-328. Https://Doi.Org/10.20886/Jphka.2008. 5.4.317-328

Dewanti, N. P., Muslim, \& Prihatiningsih, W. R. (2016). Analisis Kandungan Karbon Organik Total (KOT) Dalam Sedimen Di Perairan Sluke Kabupaten
Rembang. Jurnal Oseanografi, 5, 202210.

Donato, D. C., Kauffman, J. B., Mackenzie, R. A., Ainsworth, A., \& P, A. Z. (2012). Whole-Island Carbon Stocks In The Tropical Pacific: Implications For Mangrove Conservation And Upland Restoration. Journal Of Environmental Management, $\quad 97, \quad 89 \quad-96$. Https://Doi.Org/10.1016/J.Jenvman.20 11.12 .004

Howard, J., Hoyt, S., Isensee, K., Telszewski, M., Pidgeon, E. (Eds. . (2014). Coastal Blue Carbon: Methods For Assessing Carbon Stocks And Emissions Factors In Mangroves, Tidal Salt Marshes, And Seagrasses. In Conservation International, Intergovernmental Oceanographic Commission Of Unesco, International Union For Conservation Of Nature. Arlington, Virginia, USA.

Mahasani, I. G. A. I., Widagti, N., \& Karang, I. W. G. A. (2015). Estimasi Persentase Karbon Organik Di Hutan Mangrove Bekas Tambak, Perancak, Jembrana, Bali. Journal Of Marine And Aquatic Sciences, $\quad 1(1), \quad 14$. Https://Doi.Org/10.24843/Jmas.2015.V 1.101.14-18

Marchio, D. A., Savarese, M., Bovard, B., \& Mitsch, W. J. (2016). Carbon Sequestration And Sedimentation In Mangrove Swamps Influenced By Hydrogeomorphic Conditions And Urbanization In Southwest Florida. Forests, 7(6). Https://Doi.Org/10.3390/F7060116

Murray, B., Pendleton, L., Jenkins, W., \& Sifleet, S. (2011). Green Payments For 
Blue Carbon: Economic Incentives For Protecting Threatened Rumengan, A. P., Mantiri, D. M. H., Rompas, R., Hutahaean, A., Kepel, T. L., Paruntu, C. P., \& Kepel, R. C. (2018). Carbon Stock Assessment Of Mangrove Ecosystem In Totok Bay, Southeast Minahasa Regency, North Sulawesi , Indonesia. 11(4), 12801288.

Syukri, M. (2017). Estimasi Cadangan Karbon Vegetasi Mangrove Hubungannya Dengan Tutupan Kanopi Di Ampallas, Kelurahan Bebanga, Kecamatan Kalukku Kabupaten Mamuju Sulawesi Barat.

Supriyadi, S. (2008). Kandungan Bahan Organik Sebagai Dasar Pengelolaan Tanah Di Lahan Kering Madura. 5(2), 176-183.

Restu, N.A., Agustin, R., Terry, L., Nasir, S., Mariska, A., August, D., Devi, D.S., Yusmiana, P., Peter, M., Andreas, H. 2013. Karbon Stok dan Struktur Komunitas Mangrove Sebagai Blue Carbon di Tanjung Lesung, Banten. Pusat Penelitian dan Pengembangan Sumberdaya Pesisir \& Laut.

Verisandria, R. J., Schaduw, J. N. W., Sondak, C. F. A., Ompi, M., Rumengan, A., \& Rangan, J. (2018). Estimasi Potensi Karbon Pada Sedimen Ekosistem Mangrove Di Pesisir Taman Nasional Bunaken Bagian Utara. Jurnal Pesisir Dan Laut Tropis, 1(1), 1-17.

Zulkarnain, Marwah, S., \& Sartika, L. (2016). Melalui Analisis Backscatter Citra Satelit Radar Alos Palsar L-Band. Ecogreen, 2(2), 97-105.
CoastalHabitats. InNicholas Institute Report. 